\title{
Determination of Methanol in Gasoline and Ethanol Fuels by High-Performance Liquid Chromatography
}

\author{
Gabriella P. Dias, ${ }^{\circledR a}$ Rafael C. dos Santos, ${ }^{b}$ Renato C. Carvalho, ${ }^{c}$ Cristiane G. de Souza, ${ }^{\oplus c, d}$ \\ Amanda P. F. dos Santos, ${ }^{b}$ Débora F. de Andrade ${ }^{c}$ and Luiz A. d'Avila ${ }^{\circledR *, b}$ \\ ${ }^{a}$ Escola de Química, Universidade Federal do Rio de Janeiro, Cidade Universitária, \\ 21941-909 Rio de Janeiro-RJ, Brazil \\ ${ }^{b}$ Programa de Engenharia de Processos Químicos e Bioquímicos, Escola de Química, \\ Universidade Federal do Rio de Janeiro, Cidade Universitária, 21941-909 Rio de Janeiro-RJ, Brazil \\ 'Instituto de Química, Universidade Federal do Rio de Janeiro, Cidade Universitária, \\ 21941-909 Rio de Janeiro-RJ, Brazil \\ ${ }^{d}$ Programa de Engenharia da Nanotecnologia, \\ Instituto Alberto Luiz Coimbra de Pós-Graduação e Pesquisa de Engenharia (COPPE), \\ Universidade Federal do Rio de Janeiro, Cidade Universitária, 21941-909 Rio de Janeiro-RJ, Brazil
}

\begin{abstract}
Gasoline and ethanol fuels have been adulterated with methanol in Brazil. Methanol is not permitted in concentrations greater than $0.5 \mathrm{vol} \%$ due its toxicity but its lower price stimulates the adulteration. A new approach for quantitative analysis of methanol in gasoline and ethanol fuels is reported employing high-performance liquid chromatography coupled with refractive index $(\mathrm{RI})$ detector on $\mathrm{C} 18$ column $(250 \times 4.6 \mathrm{~mm}, 5 \mu \mathrm{m})$ using deionized water as mobile phase $\left(0.6 \mathrm{~mL} \mathrm{~min}^{-1}\right)$. The method showed good analytical performance in terms of linearity for methanol concentration ranging from 0.5 to $4.5 \mathrm{vol} \%$ (coefficient of determination $\left(\mathrm{R}^{2}\right)=0.999$ ) and from 4.0 to $12.0 \mathrm{vol} \%\left(\mathrm{R}^{2}=0.998\right)$. The recoveries (accuracy) values ranged from 98.6 to $103.2 \%$. The results indicated that the developed method is accurate and suitable for the determination of methanol in gasoline with ethanol and ethanol fuel as an alternative procedure to gas chromatography (GC)-based techniques.
\end{abstract}

Keywords: liquid chromatography, adulterant, ethanol fuel, methanol, gasoline, refractive index

\section{Introduction}

Gasoline is a petroleum derivative fuel that has a large application in the transport sector. However, the excessive use of fossil fuels is thought to increase the greenhouse effect, climate change, air pollution and acid rain. ${ }^{1}$ Gasoline is one of the main products from fractional distillation of petroleum, being a complex mixture of hydrocarbons from $\mathrm{C} 5$ to $\mathrm{C} 10$, with boiling points in the range of 30 to $215^{\circ} \mathrm{C}$, containing traces of oxygenated products, sulfur, nitrogen and metallic compounds, at low concentrations. ${ }^{2,3}$ In Brazil, gasoline is classified in " $\mathrm{A}$ " or " $\mathrm{C}$ " and "additivated gasoline". Gasoline A (no additive added) is obtained directly from refinery and $\mathrm{C}$ type is gasoline $\mathrm{A}$ with the addition of 27.0 vol $\%$ of ethanol. ${ }^{4}$

*e-mail: davila@eq.ufrj.br
Due to environmental, economic and political issues related to the worldwide petroleum usage, government, industry and academic institutions have toward their interest to renewable fuels, ${ }^{5,6}$ of which ethanol has remarkable importance as a low-emission and profitable fuel. ${ }^{7}$

Consumption of hydrated ethanol on Brazil in 2018 was about 19.385 billion of liters, a remarkable increment of $42.1 \%$ compared to 2017 . As a result, the market share of the ethanol usage (anhydrous and hydrated) in the market of fuels for Otto cycle, expressed in terms of gasoline gallon equivalent, have reached $43.8 \%$ in 2018 , the highest score since the peak value of $45.0 \%$, recorded in 2009 . World sharing of ethanol on the consumption of fuels for Otto cycle in 2018 was 25.0\% (Paraguay), 12.4\% (Thailand), $12.0 \%$ (Argentina), 9.9\% (USA), 9.5\% (Canada), $8.0 \%$ (Colombia and Uruguay), 3.5\% (China), 3.2\% (India), $1.5 \%(\mathrm{EU})$, in gasoline gallon equivalents. ${ }^{8}$ 
In 1998, the Fuel Quality Monitoring Program was established in order to survey general indicators of the quality of fuels marketed in Brazil and to identify areas with non-conformity. ${ }^{9}$ Brazilian National Agency of Petroleum, Natural Gas and Biofuels (ANP) ${ }^{10}$ pointed out that ethanol has been eventually adulterated with methanol in Brazil, which is not allowed in concentrations greater than $0.5 \mathrm{vol} \%{ }^{10}$ due to its higher toxicity. ${ }^{11,12}$

The adulteration is carried out in order to obtain economic advantages, due to the availability and the lower cost of methanol in relation to ethanol. It is important to emphasize that this adulteration damages the consumer not only because it represents a greater risk to health, since methanol has higher toxicity than ethanol, but also because of the higher fuel consumption due to the lower calorific value of methanol (approximately $40 \%$ lower than the ethanol value). ${ }^{13}$

The reference method for determining methanol content in ethanol or gasoline, described in ANP resolution No. 19 of April 15, 2015, is detailed in NBR 16041, ${ }^{14}$ issued by the Brazilian Technical Standards Association (ABNT). In this method, gas chromatography is employed to separate alcohols from the hydrocarbons that compose gasoline. Underivatized samples are carried out throughout porous fused silica column (Q type, $100 \mathrm{~m} \times 0.32 \mathrm{~mm}$ ) using high purity nitrogen. Total time for analysis is 18 and $30 \mathrm{~min}$ for ethanol and gasoline, respectively. ${ }^{10,14}$

The reference method for determining ethanol content in gasoline, described in ANP resolution No. 40 of October 25, 2013, is detailed in Brazilian standard NBR 13992,3,15 issued by ABNT. This method is known as "test of graduated test tube" and it is a simple, fast, practical and field-relevant method for investigating gasoline compliance. However, due to these characteristics, it has a measurement uncertainty of $1.0 \mathrm{vol} \%$, with the limitation of quantifying other water miscible alcohols (mainly methanol) as anhydrous ethanol fuel, since the method is not selective.

In this context, the development of analytical methods to corroborate the quality and authenticity of fuels used in Brazil is quite necessary. Various analytical techniques have been reported for the determination of fuel adulteration, like electrochemical techniques, ${ }^{16-18}$ infrared spectroscopy, ${ }^{19-29}$ Raman spectroscopy, ${ }^{30-34}$ proton nuclear magnetic resonance spectroscopy ( ${ }^{1} \mathrm{H}$ NMR), ${ }^{35,36}$ chemometrics analysis, ${ }^{30,37,38}$ gas chromatography (GC), ${ }^{38-43}$ comprehensive two-dimensional gas chromatography, ${ }^{44-46}$ high-performance liquid chromatography (HPLC) ${ }^{47-49}$ and distillation curves. . $^{50,51}$

Avila et al. ${ }^{47}$ developed an HPLC method for the selective quantification of ethanol in gasoline. In their work, the chromatographic separation was achieved in about
15 min on C18 column using methanol as mobile phase, refractive index detector (RI) and usual chromatographic conditions. The proposed method presented expanded uncertainty $(0.56 \mathrm{vol} \%)$ lower than the current reference test NBR $13992(1.0 \mathrm{vol} \%) \cdot{ }^{15} \mathrm{Also}$, it is worth pointing that methanol content was not determined.

Abreu et al. ${ }^{16}$ proposed a determination of methanol and ethanol in hydrated ethyl alcohol fuel samples applying voltammetry and multivariate calibration. Chen et al..$^{52}$ proposed a method for determination of methanol in waterethanol solution by HPLC-UV, a LiChrospher diol column and a mixture of $n$-hexane-dichloromethane (9:1) as mobile phase. Samples were derivatized using 3-bromomethyl7-methoxy-1,4-benzoxazin-2-one. The method requires an additional step of derivatization, spending $2 \mathrm{~h}$ for complete reaction.

The present study proposes the first application of highperformance liquid chromatography with refractive index detection (HPLC-RI) to develop a quick and less expensive method for quantifying methanol content in gasoline and ethanol fuel.

\section{Experimental}

\section{Standard samples of methanol in ethanol}

Methanol and ethanol HPLC grade were purchased from Tedia (São Paulo, Brazil). Two analytical curves were made for ranges of 0.5-4.5 and 4.0-12.0 vol\% by diluting 10.0 and $50.0 \mathrm{vol} \%$ mother solution of methanol in ethanol, respectively. The standard solutions were prior diluted with HPLC-grade ethanol to $10.0 \%$ for analysis by applying the proposed HPLC method. The diluted solutions were used as standards for linearity evaluation.

Preparation of ethanol fuel and gasoline samples for analysis

Twenty ethanol fuel samples with different quantities of methanol (0.5 to 9.6 vol\%, determined by gas chromatography according to NBR 16041) ${ }^{14}$ were diluted at 20.0 vol\% using Milli-Q water (Millipore, Bedford, USA) (see Figure 1). Ethanol fuel was supplied by several gas stations and support was provided by the Fuel and Petroleum Products Laboratory, located at School of Chemistry, UFRJ (LABCOM/UFRJ).

Gasoline A was fortified with $27.0 \mathrm{vol} \%$ of alcohol (methanol + ethanol) to provide eight samples with methanol content from 0.0 to $12.0 \mathrm{vol} \%$. All the fortified samples of gasoline were submitted to the test of graduated test tube ${ }^{15}$ to extract the alcohol fraction (see Figure 1). 


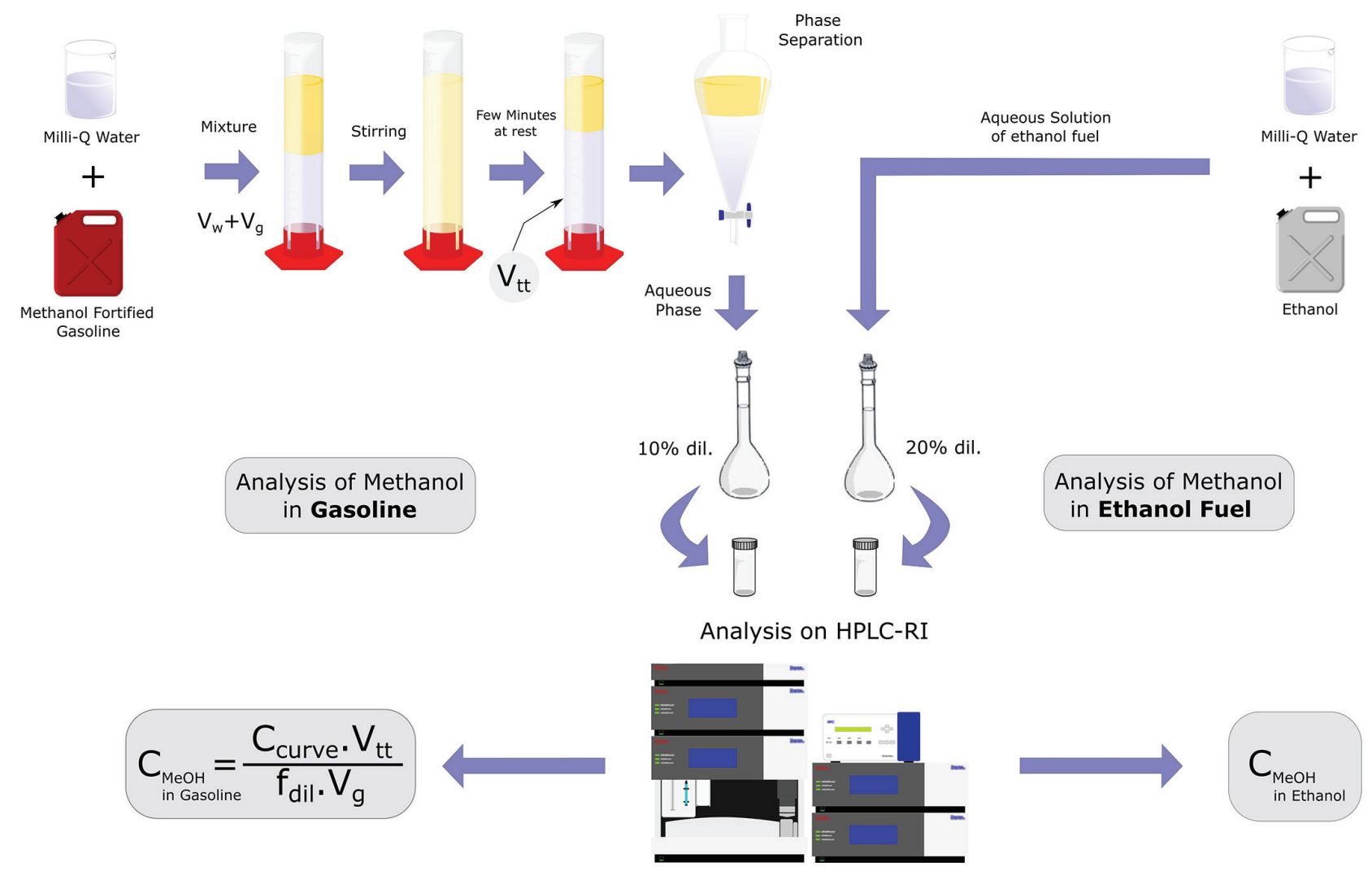

Figure 1. Procedure of methanol analysis in gasoline and ethanol fuel samples by HPLC-RI. $\mathrm{V}_{\mathrm{w}}=$ Milli- $\mathrm{Q}$ water volume; $\mathrm{V}_{\mathrm{g}}=$ gasoline volume; $\mathrm{V}_{\mathrm{tt}}=\mathrm{aqueous}$ phase volume; $\mathrm{f}_{\text {dil }}=$ dilution factor; $\mathrm{C}_{\mathrm{MeOH}}=$ methanol concentration (vol\%) and $\mathrm{C}_{\text {curve }}=$ exact methanol concentration (vol\%) of standard samples (analytical curve) injected on HPLC-RI. HPLC-RI: high-performance liquid chromatography and refractive index detector; MeOH: methanol.

$8.0 \mathrm{~mL}$ of gasoline $\left(\mathrm{V}_{\mathrm{g}}\right)$ and $8.0 \mathrm{~mL}$ of Milli-Q water $\left(\mathrm{V}_{\mathrm{w}}\right)$ were mixed and homogenized for 10 times, at $18-23^{\circ} \mathrm{C}$. The aqueous phase volume $\left(\mathrm{V}_{\mathrm{tt}}\right)$ with the alcohols was measured, collected and diluted at 10.0 vol\% using Milli-Q water. Milli-Q water was used instead of $10 \% \mathrm{NaCl}$ solution in order to avoid the deposition of salt in the chromatograph tubings, fittings and column, as well as, excessive system overpressure. To quantify methanol content in fortified gasoline samples, it was necessary to adequate the data from analytical curve of methanol in ethanol fuel $\left(\mathrm{C}_{\text {curve }}\right.$ (methanol concentration of standard samples injected on HPLC-RI), see Figure 1). The gasoline A used on samples preparation was provided by the Fuel and Petroleum Products Laboratory, located at School of Chemistry, UFRJ (LABCOM/ UFRJ). Samples of gasoline containing methanol were not found on commercial suppliers.

\section{HPLC proposed method (HPLC-RI)}

Analyses were carried out using a high-performance liquid chromatograph Dionex UltiMate ${ }^{\mathrm{TM}} 3000$ quaternary pump, a RefractoMax 521 refractive index detector and an UltiMate $^{\mathrm{TM}}$ WPS-3000 autosampler (Thermo Scientific, Massachusetts, USA) with a $300.0 \mu \mathrm{L}$ sample loop. An
Acclaim $^{\mathrm{TM}}$ column (Thermo Scientific, Massachusetts, USA) measuring $250.0 \mathrm{~mm}$ long and $4.6 \mathrm{~mm}$ internal diameter (I.D.) was used with an octadecylsilane (C18) phase with $5.0 \mu \mathrm{m}$ particle size and $120.0 \AA$ A pore diameter. The mobile phase was $100 \%$ Milli-Q water, degassed ultrasonically prior to use. The chromatographic conditions were as follows: flow-rate at $0.6 \mathrm{~mL} \mathrm{~min}{ }^{-1}$, injection volume of $20.0 \mu \mathrm{L}$, column oven and detector temperature at $30.0{ }^{\circ} \mathrm{C}$ and $8.0 \mathrm{~min}$ for total run time. Gasoline and ethanol fuel samples were diluted at 10.0 and $20.0 \mathrm{vol} \%$, respectively, using Milli-Q water as diluent. The results were analyzed by Chromeleon 6.80 SR11 software (Thermo Scientific, Massachusetts, USA). Mobile phase and samples were filtered before injection using $0.2 \mu \mathrm{m}$ polytetrafluoroethylene (PTFE) membrane filter (Millipore, Bedford, USA).

\section{GC conditions}

Ethanol fuel and gasoline samples were analyzed by GC without a pre-treatment, according to NBR 16041. ${ }^{14}$ Analyses were done using an Agilent 7890A gas chromatograph (Agilent Technologies, California, USA) with a flame ionization detector and an Agilent 
7683A autosampler (Agilent Technologies, California, USA). An Agilent PoraPLOT Q-HT capillary column $(100 \mathrm{~m} \times 0.32 \mathrm{~mm}$ I.D., $10 \mu \mathrm{m}$ film thickness, Agilent Technologies, California, USA) based on styrene/ divinylbenzene phase was connected to a particle trap $(2.5 \mathrm{~m} \times 0.32 \mathrm{~mm})$. Flow-rate of carrier gas nitrogen was set at $30.0 \mathrm{~mL} \mathrm{~min}^{-1}$. The temperatures at injector and detector were set at 250.0 and $280.0{ }^{\circ} \mathrm{C}$, respectively, and split injection $(0.5 \mu \mathrm{L}$ for each injection) was used. Oven temperature program was as follows: $85.0^{\circ} \mathrm{C}$ for 2.0 min followed by heating ramp of $35{ }^{\circ} \mathrm{C} \mathrm{min}^{-1}$ until reach $260.0{ }^{\circ} \mathrm{C}$, kept at that temperature for $11.0 \mathrm{~min}$. Chromatograms were analyzed using Agilent OpenLAB software (Agilent Technologies, California, USA). Total time of analysis was $18.0 \mathrm{~min}$.

\section{Validation procedure}

The proposed method was validated according to ICH guidelines, ${ }^{53}$ in terms of the following analytical parameters: linearity, limit of detection (LOD), limit of quantification (LOQ), precision and accuracy.

\section{Linearity}

Linearity parameter was determined by injection in triplicate of standard solutions corresponding to each point used to construct the analytical curve. Two analytical curves ( $a$ and $b$ ) were plotted in the range of $0.5-12.0 \mathrm{vol} \%$ of methanol in ethanol samples and fitted using least squares linear regression. Curve a ranged from 0.5 to $4.5 \mathrm{vol} \%$ ( 0.5 , $1.5,2.5,3.5$ and 4.5 vol\%) and curve $b$ ranged from 4.0 to $12.0 \mathrm{vol} \%$ (4.0, 6.0, 8.0, 10.0 and $12.0 \mathrm{vol} \%$ ).

Homogeneity of variances was evaluated by Cochran test, according to equation 1 .

$\mathrm{C}=\frac{\mathrm{s}_{\max }^{2}}{\sum_{\mathrm{i}=1}^{\mathrm{k}} \mathrm{s}_{\mathrm{i}}^{2}}$

where $\mathrm{s}_{\max }^{2}$ is the largest variance and $\sum_{\mathrm{i}=1}^{\mathrm{k}} \mathrm{s}_{\mathrm{i}}^{2}$ is the sum of all the variances of the samples.

\section{Limit of detection and limit of quantification}

The LOD and LOQ were calculated according to equations 2 and 3 .

$$
\begin{aligned}
& \mathrm{LOD}=3.3 \frac{\sigma_{\mathrm{LC}}}{\mathrm{S}} \\
& \mathrm{LOQ}=10 \frac{\sigma_{\mathrm{LC}}}{\mathrm{S}}
\end{aligned}
$$

where $\sigma_{\mathrm{LC}}$ is the standard deviation of the lowest concentration (LC) tested and $\mathrm{S}$ is the slope of the analytical curve.

\section{Precision}

Repeatability and intermediate precision were also used to evaluate precision of the method. Repeatability was verified for three different concentrations (lower, middle and higher), in triplicate. Lower, middle and higher concentrations were $0.5,2.5$ and $4.5 \mathrm{vol} \%$ for curve a and 4.0, 8.0 and 12.0 vol\% for curve b. Intermediate precision was also evaluated using analytical curves constructed by two different analysts, in the same laboratory, and the results were compared by one-way ANOVA (analysis of variance). Precision was expressed as relative standard deviation (RSD, in \%), according to equation 4.

$\operatorname{RSD}(\%)=\frac{\sigma}{\overline{\mathrm{C}}} 100$

where $\sigma$ stands for the standard deviation of the lowest concentration standard and $\overline{\mathrm{C}}$ is the average concentration.

\section{Accuracy}

Accuracy was expressed as recovery (R, in \%) and calculated at different concentration levels (lower, middle and higher) of methanol in ethanol (triplicate) for each analytical curve. To the first calibration curve the concentrations were $0.5,2.5$ and $4.5 \mathrm{vol} \%$ and to the second curve, 4.0, 8.0 and 12.0 vol\%. Accuracy was calculated by equation 5 .

$\mathrm{R}(\%)=\frac{\mathrm{C}_{\mathrm{m}}}{\mathrm{C}_{\mathrm{ex}}} 100$

where $C_{m}$ and $C_{e x}$ stand for the measured and expected concentrations, respectively.

\section{HPLC-RI and reference GC methods comparison}

A comparative study was carried out between the standard reference method $^{14}(\mathrm{GC})$, recommended by ANP, for the analysis of the methanol content in fuel samples, and the proposed method (HPLC-RI), using the paired $t$-test, according to equation $6 .^{54}$

$t_{\text {calc }}=\frac{\overline{X_{C}} \sqrt{N}}{\mathrm{~s}_{\mathrm{i}}}$

where $\overline{\mathrm{X}_{\mathrm{C}}}$ is the mean of the differences, $\mathrm{s}_{\mathrm{i}}$ is the standard deviation of the differences and $\mathrm{N}$ is the number of pairs. 


\section{Results and Discussion}

\section{Chromatographic parameters}

All the samples (standards and fuel samples) were analyzed by HPLC and had the same gaussian chromatographic profile, as shown in Figure 2. In order to perform a clear integration of each peak, improved chromatographic conditions were used, such as flow-

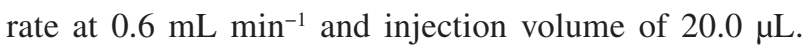
Aqueous phase from extraction step (gasoline samples) and ethanol fuel samples were diluted at 10.0 and $20.0 \mathrm{vol} \%$, respectively, using Milli-Q water as diluent. Since it was achieved an improved set of conditions that provided

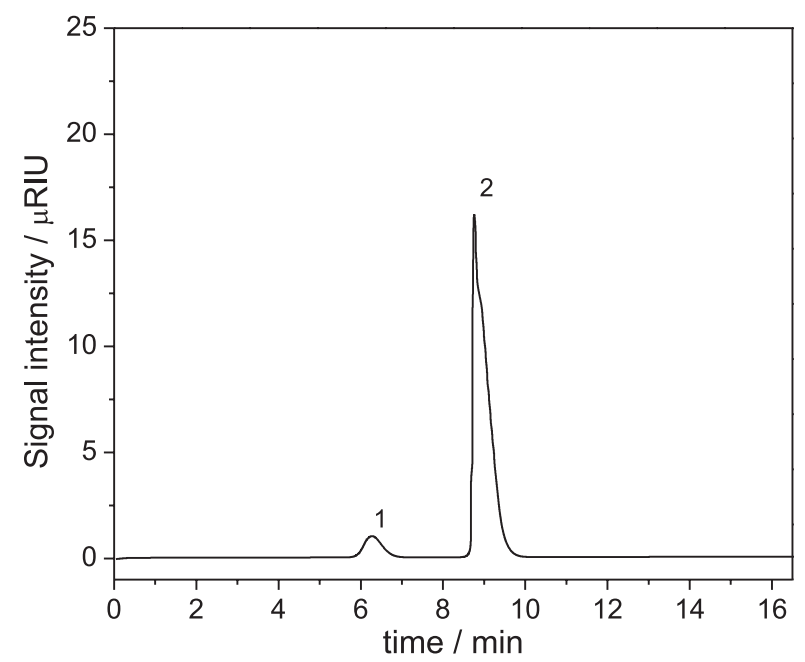

Figure 2. HPLC chromatogram of a standard ethanol sample containing $0.5 \mathrm{vol} \%$ of methanol. Chromatographic conditions: flow-rate at $0.6 \mathrm{~mL} \mathrm{~min}{ }^{-1}$, injection volume of $20.0 \mu \mathrm{L}$ and dilution of $20.0 \mathrm{vol} \%$. Peaks: 1: methanol; 2: ethanol. RIU: signal intensity in refractive index units.

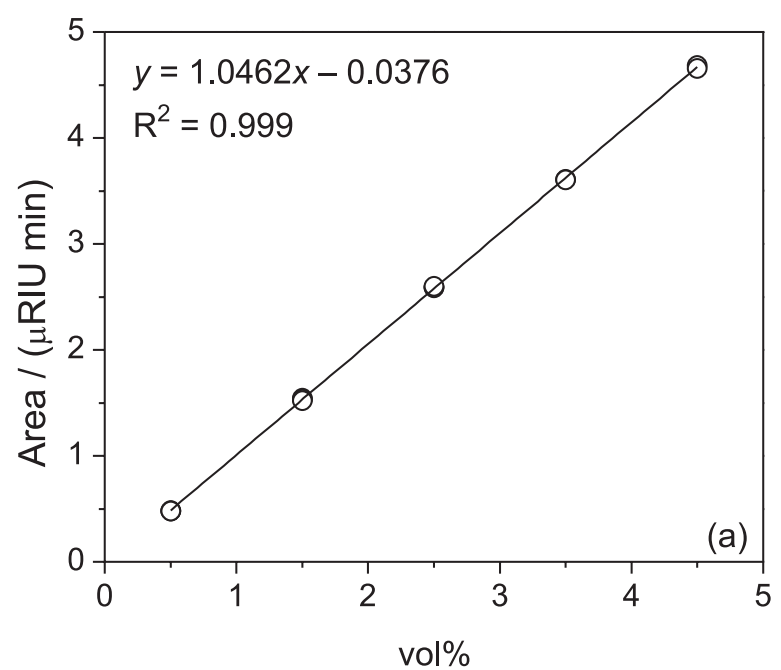

balance between time of analysis and good peak resolution, it was performed the method validation.

\section{Validation procedure}

\section{Linearity}

For plotting each analytical curve, five standard samples of ethanol containing methanol were analyzed by HPLC in triplicate, as shown in Figure 3. The linearity was evaluated in the range of 0.5-4.5 and 4.0-12.0 vol\%. Determination coefficient $\left(\mathrm{R}^{2}\right)$ was higher than the acceptance criteria (0.990), ${ }^{55,56}$ pointing out good linearity at the established ranges.

The concentrations worked were split in two curves in order to guarantee the accuracy of the estimates at low and high methanol concentration levels.

The Cochran test was used, taking into account triplicates and the number of the concentrations $(\mathrm{k}=5)$. For curves $a$ and $b$, the $C$ value calculated was $C=0.500$ and 0.354 , respectively, both was lower than the tabulated value (0.684) showing that the variances were homoscedastic.

\section{Limit of detection and limit of quantification}

For the lowest concentrations, LOD and LOQ values were 0.0053 and $0.016 \mathrm{vol} \%$, respectively (see Table 1 ). For the highest concentrations, LOD and LOQ values were 0.0048 and 0.014 vol\% (see Table 1). These limits showed no relevant differences when comparing the analytical curves. The results demonstrated that it is possible to differentiate and quantify samples differing from each other at about 0.014 vol\% on methanol content. Also, it is noteworthy that if the regulatory standards restrict the tolerance range to lower levels $(<0.5$ vol\%), the present method is still applicable, since its LOQ is 0.01 vol\%.

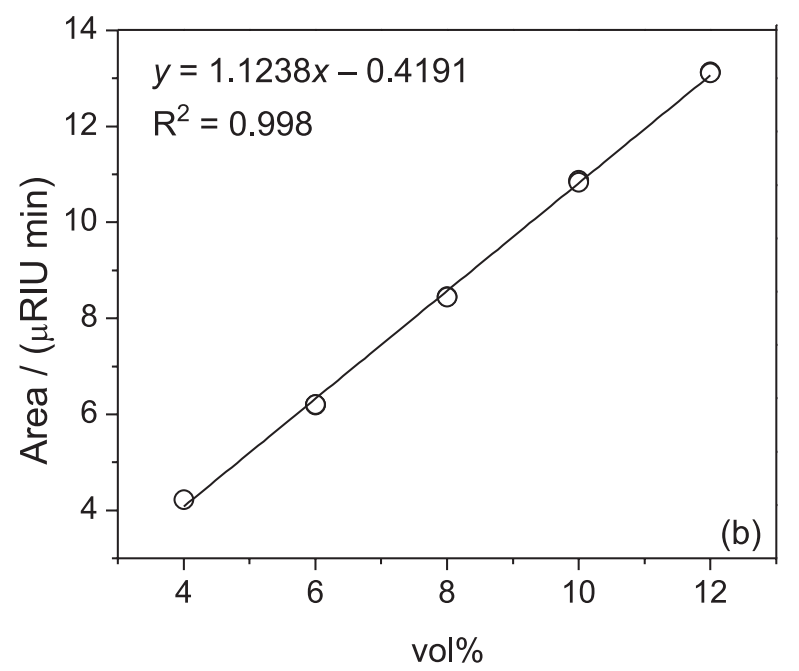

Figure 3. Analytical curves of methanol ranging (a) from 0.5 to $4.5 \mathrm{vol} \%$ and (b) from 4.0 to 12.0 vol\% obtained by HPLC analysis. RIU: signal intensity in refractive index units. 
Table 1. Validation parameters for HPLC-RI method

\begin{tabular}{|c|c|c|}
\hline Parameter & Lowest concentrations & Highest concentrations \\
\hline Linearity range $(\mathrm{n}=5) /$ vol $\%$ & $0.5-4.5$ & $4.0-12.0$ \\
\hline Regression equation & $y=1.0462 x-0.0376^{\mathrm{a}}$ & $y=1.1238 x-0.4191^{\mathrm{a}}$ \\
\hline Determination coefficient $\left(\mathrm{R}^{2}\right)$ & 0.9999 & 0.9988 \\
\hline $\mathrm{LOD} / \mathrm{vol} \%$ & 0.0053 & 0.0048 \\
\hline $\mathrm{LOQ} /$ vol\% & 0.016 & 0.014 \\
\hline \multicolumn{3}{|l|}{ Repeatability (RSD) ${ }^{\mathrm{b}} / \%$} \\
\hline Lower & 0.354 & 0.039 \\
\hline Middle & 0.288 & 0.044 \\
\hline Higher & 0.308 & 0.051 \\
\hline \multicolumn{3}{|l|}{ Recovery $^{\mathrm{b}} / \%$} \\
\hline Lower & $99.07 \pm 0.01$ & $103.26 \pm 0.09$ \\
\hline Middle & $100.60 \pm 0.01$ & $98.61 \pm 0.08$ \\
\hline Higher & $100.09 \pm 0.01$ & $100.46 \pm 0.04$ \\
\hline
\end{tabular}

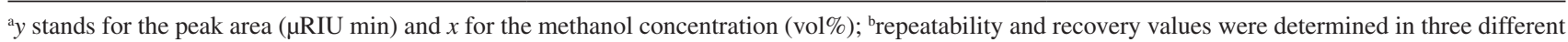
concentrations (lower, middle and higher), in triplicate, for each analytical curve. Lower, middle and higher concentrations were $0.5,2.5$ and 4.5 vol\% for the first calibration curve and 4.0, 8.0 and 12.0 vol\% for the second curve. HPLC-RI: high-performance liquid chromatography and refractive index detector; LOD: limit of detection; LOQ: limit of quantification, RSD: relative standard deviation.

\section{Precision}

RSD values lower than 5\% show good precision in terms of repeatability (Table 1). ${ }^{55,56}$ Intermediate precision was evaluated from data of different curves, by means of one-way ANOVA. The $F$ value calculated by $\operatorname{ANOVA}(F=0.072)$ was lower than the tabulated value (4.196), showing that there are not statistical differences among the means.

\section{Accuracy}

Accuracy values were obtained in the range of 98.61 to $103.26 \%$. The overall mean recovery was found to be $99.92 \pm 0.01 \%$ for the lowest concentrations and $100.77 \pm 0.07 \%$ for the highest concentrations, showing good agreement between experimental and calculated values. The accuracy results were found within acceptance criteria (70-120\%). ${ }^{55,56}$ Table 1 shows the validation parameters of the proposed analytical method.

\section{Comparison between the HPLC-RI and reference GC methods}

We performed a comparison between the proposed HPLC method and the reference method ${ }^{14}$ (GC), according to ANP, in order to provide the partial validation of the methodology. The appropriate equations for analytical curves were used to quantify methanol concentrations determined by HPLC in the 20 ethanol fuel samples tested. Table 2 shows the results for HPLC analysis of methanol content in the mentioned samples, performed in triplicate and compared to the results obtained by gas chromatography (GC).
Table 2. Methanol content on verification samples (ethanol fuel samples), determined by HPLC-RI and GC

\begin{tabular}{lcc}
\hline \multirow{2}{*}{ Sample } & \multicolumn{2}{c}{ Methanol content \pm SD / vol\% } \\
\cline { 2 - 3 } 1 & HPLC-RI & GC \\
2 & $0.487 \pm 0.001$ & $0.70 \pm 0.02^{\mathrm{a}}$ \\
3 & $0.704 \pm 0.004$ & $0.60 \pm 0.02^{\mathrm{a}}$ \\
4 & $0.934 \pm 0.001$ & $0.80 \pm 0.02^{\mathrm{a}}$ \\
5 & $1.190 \pm 0.002$ & $1.20 \pm 0.02^{\mathrm{a}}$ \\
6 & $1.258 \pm 0.001$ & $1.30 \pm 0.02^{\mathrm{a}}$ \\
7 & $1.508 \pm 0.003$ & $1.30 \pm 0.02^{\mathrm{a}}$ \\
8 & $1.562 \pm 0.006$ & $1.50 \pm 0.02^{\mathrm{a}}$ \\
9 & $1.855 \pm 0.004$ & $2.00 \pm 0.02^{\mathrm{a}}$ \\
10 & $2.191 \pm 0.017$ & $2.00 \pm 0.02^{\mathrm{a}}$ \\
11 & $2.350 \pm 0.003$ & $2.70 \pm 0.02^{\mathrm{a}}$ \\
12 & $2.721 \pm 0.002$ & $2.80 \pm 0.02^{\mathrm{a}}$ \\
13 & $2.763 \pm 0.002$ & $3.10 \pm 0.65^{\mathrm{b}}$ \\
14 & $3.594 \pm 0.011$ & $3.60 \pm 0.65^{\mathrm{b}}$ \\
15 & $5.472 \pm 0.009$ & $5.50 \pm 0.65^{\mathrm{b}}$ \\
16 & $6.317 \pm 0.034$ & $6.00 \pm 0.65^{\mathrm{b}}$ \\
17 & $7.051 \pm 0.018$ & $7.10 \pm 0.65^{\mathrm{b}}$ \\
18 & $7.909 \pm 0.030$ & $8.20 \pm 0.65^{\mathrm{b}}$ \\
19 & $7.980 \pm 0.086$ & $8.10 \pm 0.65^{\mathrm{b}}$ \\
\hline 0 & $9.245 \pm 0.027$ & $9.40 \pm 0.65^{\mathrm{b}}$ \\
\hline 0 & $9.607 \pm 0.016$ & $9.50 \pm 0.65^{\mathrm{b}}$ \\
\hline
\end{tabular}

${ }^{\mathrm{a} O v e r a l l ~ m e a n ~ d e v i a t i o n ~ f o r ~ a n a l y t i c a l ~ c u r v e s ~ f r o m ~} 0.5-4.5$ vol $\%$; boverall mean deviation for analytical curves from 4.0-12.0 vol\%. HPLC-RI: highperformance liquid chromatography and refractive index detector; SD: standard deviation; GC: gas chromatography. 
Results obtained from HPLC-RI and GC were compared by means of paired $t$-test. The $t$-value calculated $(0.641)$ was lower than the tabulated value (2.093, two-tailed), indicating no statistical differences ( $95 \%$ confidence) between the methods.

Table 3 shows the results of HPLC analysis of methanol content in 8 verification samples (gasoline samples) performed in triplicate, comparing to the results obtained by gas chromatography (GC). The results obtained by HPLC-RI and GC were compared by means of paired $t$-test. The $t$-value calculated (2.127) was lower than the tabulated value (2.365), showing that there are not statistical differences (95\% confidence) among the methods.

Data presented on Tables 2 and 3 were plotted in order to highlight the accordance among the results obtained from the HPLC-RI method and the reference method

Table 3. Methanol content on verification samples (gasoline samples), determined by HPLC-RI and GC

\begin{tabular}{lcc}
\hline \multirow{2}{*}{ Sample } & \multicolumn{2}{c}{ Methanol content \pm SD / vol $\%$} \\
\cline { 2 - 3 } 1 & HPLC-RI & GC \\
\hline 2 & $<$ LOQ & $<0.07 \pm 0.02^{\mathrm{a}}$ \\
3 & $0.50 \pm 0.01$ & $0.50 \pm 0.02^{\mathrm{a}}$ \\
4 & $2.60 \pm 0.01$ & $2.90 \pm 0.02^{\mathrm{a}}$ \\
5 & $4.90 \pm 0.07$ & $5.00 \pm 0.65^{\mathrm{b}}$ \\
6 & $5.80 \pm 0.01$ & $5.60 \pm 0.65^{\mathrm{b}}$ \\
7 & $6.30 \pm 0.01$ & $6.60 \pm 0.65^{\mathrm{b}}$ \\
8 & $7.30 \pm 0.02$ & $7.60 \pm 0.65^{\mathrm{b}}$ \\
\hline
\end{tabular}

${ }^{\mathrm{a} O v e r a l l ~ m e a n ~ d e v i a t i o n ~ f o r ~ a n a l y t i c a l ~ c u r v e s ~ f r o m ~ 0.5-4.5 ~ v o l \% ; ~}$ boverall mean deviation for analytical curves from 4.0-12.0 vol\%. HPLC-RI: high-performance liquid chromatography and refractive index detector; SD: standard deviation; GC: gas chromatography; LOQ: limit of quantification.

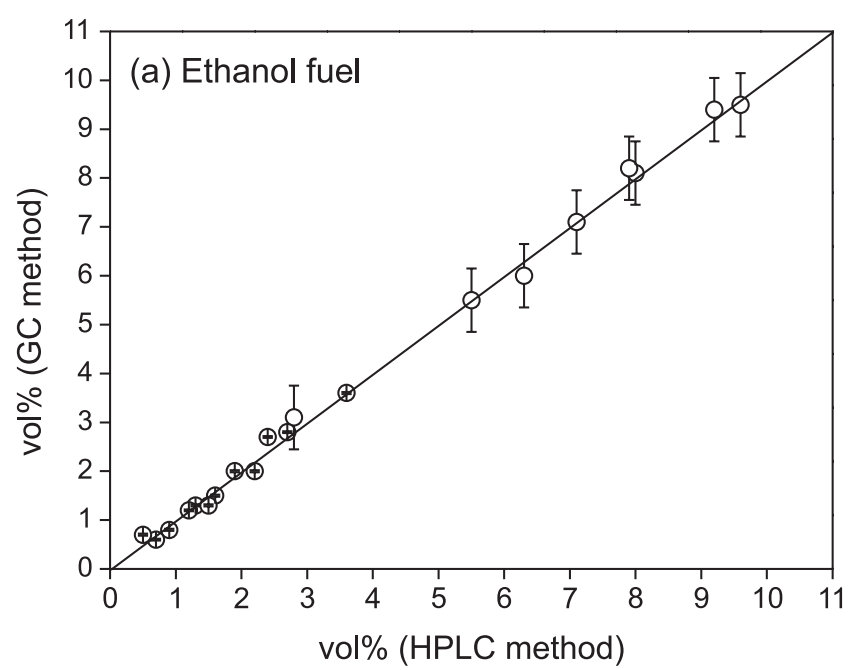

(GC). Standard deviations are shown for all values (see Figure 4). It is interesting to notice that the GC method presents a large deviation for samples with high methanol concentrations. Deviations estimated on our method were almost homogeneous for all the samples (ethanol fuel and gasoline).

\section{Conclusions}

A simple, fast, precise, accurate and sensitive HPLC-RI for determination of methanol in gasoline with ethanol and ethanol fuels was successfully implemented, without derivatization of compound under analysis and with no interference observed in conditions employed.

Performing the test of graduated test tube method, uniquely, it is not possible to measure the ethanol content in gasoline containing methanol as adulterant. Therefore, the developed method is complementary to the test of graduated test tube method. When the former points out the absence of methanol, the test of graduated test tube could be safely applied to quantify ethanol on gasoline samples.

The response of the method was found to be linear in the range of 0.5-4.5 and 4.0-12.0 vol\% of methanol, and it proved to be precise and accurate. Furthermore, the chromatographic method was validated and presented acceptable values for all the method validation parameters tested. Also, it is a resource-saving method with the utilization of water as solvent and common stationary phases.

Finally, it must be highlighted that this method is in accordance among the results obtained with reference method (GC) and presents itself as an alternative procedure to reference GC-based technique.

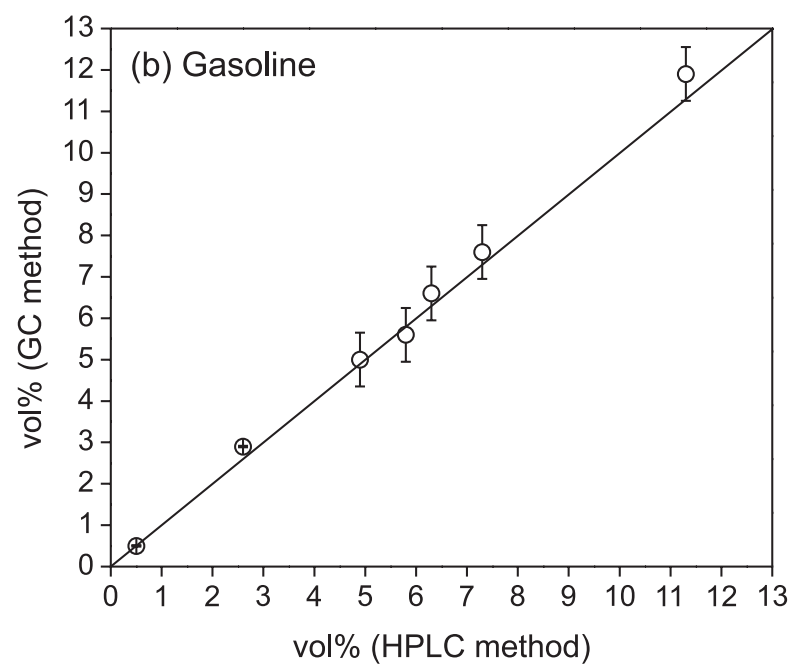

Figure 4. Comparison between methanol concentrations determined by means of the proposed HPLC method and GC method for (a) ethanol fuel and (b) gasoline samples. 


\section{Acknowledgments}

The authors are grateful to CNPq for financial support.

\section{Author Contributions}

Gabriella P. Dias was responsible for the investigation and methodology; Rafael C. dos Santos for the conceptualization, formal analysis, investigation, methodology, project administration, supervision, writing: original draft, review and editing; Renato C. Carvalho for the conceptualization, supervision, writing: review and editing; Cristiane G. de Souza for the conceptualization, formal analysis, investigation, methodology, project administration, supervision, validation, writing: original draft, review and editing; Amanda P. F. dos Santos for the review; Débora F. de Andrade for the conceptualization, formal analysis, investigation, methodology, project administration, resources, supervision, validation, writing: original draft, review and editing; Luiz A. d'Avila for the conceptualization, formal analysis, investigation, methodology, project administration, resources, supervision, validation, writing: original draft, review and editing.

\section{References}

1. Dermibas, A.; Energy Convers. Manage. 2009, 50, 2239.

2. Goodger, E. M.; Hydrocarbon Fuels: Production, Properties and Performance of Liquids and Gases; Wiley: New York, USA, 1975.

3. http://legislacao.anp.gov.br/?path=legislacao-anp/resolanp/2013/outubro\&item=ranp-40-2013, accessed in December 2019.

4. https://www.normasbrasil.com.br/norma/portaria-75-2015_ 281775.html, accessed in December 2019.

5. Agarwal, A. K.; Prog. Energy Combust. Sci. 2007, 33, 233.

6. Oumer, A. N.; Hasan, M. M.; Baheta, A. T.; Mamat, R.; Abdullah, A. A.; Renewable Sustainable Energy Rev. 2018, 88, 82 .

7. Naik, S. N.; Goud, V. V.; Rout, P. K.; Dalai, A. K.; Renewable Sustainable Energy Rev. 2010, 14, 578.

8. Nastari, P.; Eletrificação com Biocombustíveis; available at http:// www.anp.gov.br/images/Palestras/Matriz-Veicular-2019/08Plinio_Nastari-Datagro.pdf, accessed in December 2019.

9. http://legislacao.anp.gov.br/?path=legislacao-anp/resolanp/2011/fevereiro\&item=ranp-8-2011, accessed in December 2019.

10. http://legislacao.anp.gov.br/?path=legislacao-anp/resolanp/2015/abril\&item=ranp-19-2015, accessed in December 2019.
11. Kruse, J. A.; Intensive Care Med. 1992, 18, 391.

12. Jahan, K.; Mahmood, D.; Fahim, M.; J. Pharm. BioAllied Sci. 2015, 7, 60 .

13. Martins, G. B. C.; Montenegro, M. A.; Suarez, P. A. Z.; Quim. Nova 2015, 38, 280.

14. ABNT NBR 16041: Fuel Ethanol-Determination of Methanol and Ethanol Contents by Gas Chromatography; ABNT: Campos Elíseos, SP, Brazil, 2015.

15. ABNT NBR 13992: Automotive Gasoline - Determination of Anhydrous Ethanol Fuel Content; ABNT: Campos Elíseos, SP, Brazil, 2015.

16. Abreu, R. E. L.; Paz, J. E. M.; Silva, A. C.; Pontes, M. J. C.; Lemos, S. G.; Fuel 2015, 156, 20.

17. Pereira, P. F.; Sousa, R. M. F.; Munoz, R. A. A.; Richter, E. M.; Fuel 2013, 103, 725.

18. Silva, A. C.; Paz, J. E. M.; Pontes, L. F. B. L.; Lemos, S. G.; Pontes, M. J. C.; Electrochim. Acta 2013, 111, 160.

19. Carneiro, H. S. P.; Medeiros, A. R. B.; Oliveira, F. C. C.; Aguiar, G. H. M.; Rubim, J. C.; Suarez, P. A. Z.; Energy Fuels 2008, 22, 2767.

20. Silva, A. C.; Pontes, L. F. B. L.; Pimentel, M. F.; Pontes, M. J. C.; Talanta 2012, 93, 129.

21. Fernandes, H. L.; Raimundo Jr., I. M.; Pasquini, C.; Rohwedder, J. J. R.; Talanta 2008, 75, 804.

22. Corsetti, S.; Zehentbauer, F. M.; McGloin, D.; Kiefer, J.; Fuel 2015, 141, 136.

23. Lutz, O. M. D.; Bonn, G. K.; Rode, B. M.; Huck, C. W.; Anal. Chim. Acta 2014, 826, 61.

24. Mabood, F.; Gilani, S. A.; Albroumi, M.; Alameri, S.; Al Nabhani, M. M. O.; Jabeen, F.; Hussain, J.; Al-Harrasi, A.; Boque, R.; Farooq, S.; Hamaed, A. M.; Naureen, Z.; Khan, A.; Hussain, Z.; Fuel 2017, 197, 388.

25. Milanez, K. D. T. M.; Silva, A. C.; Paz, J. E. M.; Medeiros, E. P.; Pontes, M. J. C.; Microchem. J. 2016, 124, 121.

26. Concklin Jr., A.; Goldcamp, M. J.; Barrett, J.; J. Chem. Educ. 2014, 91, 889.

27. Maldonado, M.; Barreiro, P.; Gutierrez, R.; Vergara, G.; Fuel Process. Technol. 2018, 171, 287.

28. Correia, R. M.; Domingos, E.; Cao, V. M.; Araujo, B. R. F.; Sena, S.; Pinheiro, L. U.; Fontes, A. M.; Aquino, L. F. M.; Ferreira, E. C.; Filgueira, P. R.; Romao, W.; Talanta 2018, 176, 26.

29. Teixeira, L. S. G.; Oliveira, F. S.; Santos, H. C.; Cordeiro, P. W. L.; Almeida, S. Q.; Fuel 2008, 87, 346.

30. Ardila, J. A.; Soares, F. L. F.; Farias, M. A. S.; Carneiro, R. L.; Anal. Lett. 2017, 50, 1126.

31. Fortunato, F. M.; Vieira, A. L.; Neto, J. A. G.; Donati, G. L.; Jones, B. T.; Microchem. J. 2017, 133, 76.

32. Xu, Q.; Ye, Q.; Cai, H.; Qu, R.; Sens. Actuators, B 2010, 146, 75 .

33. Numata, Y.; Iida, Y.; Tanaka, H.; J. Quant. Spectrosc. Radiat. Transfer 2011, 112, 1043. 
34. Ye, Q.; Xu, Q.; Yu, Y.; Qu, R.; Fang, Z.; Opt. Commun. 2009, 282, 3785 .

35. Neto, A. C.; Oliveira, E. C. S.; Lacerda Jr., V.; Castro, E. V. R.; Romao, W.; Silva, R. C.; Pereira, R. G.; Sten, T.; Filgueiras, P. R.; Poppi, R. J.; Fuel 2014, 135, 387.

36. Turanov, A.; Khitrin, A. K.; Fuel 2014, 137, 335.

37. Bueno, L.; Paixão, T. R. L. C.; Talanta 2011, 87, 210.

38. Wiedemann, L. S. M.; d'Avila, L. A.; Azevedo, D. A.; J. Braz. Chem. Soc. 2005, 16, 139.

39. Wiedemann, L. S. M.; d'Avila, L. A.; Azevedo, D. A.; Fuel 2005, $84,467$.

40. Wang, M.; Wang, J.; Choong, Y.; Food Chem. 2004, 86, 609.

41. Wang, M.; Wang, J.; Choong, Y.; J. Food Compos. Anal. 2004, $17,187$.

42. Nespeca, M. G.; Munhoz, J. F. V. L.; Flumignan, D. L.; de Oliveira, J. E.; Fuel 2018, 215, 204.

43. Moreira, L. S.; d'Avila, L. A.; Azevedo, D. A.; Chromatographia 2003, 58, 501.

44. Godoy, L. A. F.; Ferreira, E. C.; Pedroso, M. P.; Fidelis, C. H. V.; Augusto, F.; Poppi, R. J.; Anal. Lett. 2008, 41, 1603.

45. Godoy, L. A. F.; Pedroso, M. P.; Ferreira, E. C.; Augusto, F.; Poppi, R. J.; J. Chromatogr. A 2011, 1218, 1663.

46. Pedroso, M. P.; de Godoy, L. A. F.; Ferreira, E. C.; Poppi, R. J.; Augusto, F.; J. Chromatogr. A 2008, 1201, 176.

47. Avila, L. M.; dos Santos, A. P. F.; de Mattos, D. I. M.; Souza, C. G.; Andrade, D. F.; d'Avila, L. A.; Fuel 2018, 212, 236.
48. Kaminski, M.; Kartanowicz, R.; Przyjazny, A.; J. Chromatogr. A 2004, 1029, 77.

49. Saczk, A. A.; Okumura, L. L.; de Oliveira, M. F.; Zanoni, M. V. B.; Stradiotto, N. R.; Chromatographia 2006, 63, 45.

50. Aleme, H. G.; Costa, L. M.; Barbeira, P. J. S.; Talanta 2009, $78,1422$.

51. Oliveira, F. S.; Teixeira, L. S. G.; Araujo, M. C. U.; Korn, M.; Fuel 2004, 83, 917.

52. Chen, S.; Wu, H.; Yen, C.; Wu, S.; Lin, S.; Kou, H.; J. Chromatogr. A 1998, 799, 93.

53. International Council for Harmonisation (ICH); Harmonised Tripartite Guideline - Validation of Analytical Procedures: Text and Methodology - Q2 (R1); Geneva, Switzerland, 2005. Available at https://database.ich.org/sites/default/files/ Q2_R1_Guideline.pdf, accessed in December 2019.

54. Miller, J. C.; Miller, J. N.; Estatística para Química Analítica, $2^{\text {nd }}$ ed.; Addison-Wesley: Wilmington, 1993.

55. Leite, F.; Validação em Análise Química, 5 $^{\text {th }}$ ed.; Editora Átomo: São Paulo, 2008.

56. Lanças, F. M.; Validação de Métodos Cromatográficos de Análise; Editora RiMA: São Carlos, 2004.

Submitted: September 6, 2019

Published online: December 12, 2019 